\title{
Construction of a competing endogenous RNA network using differentially expressed IncRNAs, miRNAs and mRNAs in non-small cell lung cancer
}

\author{
XI-WEN WANG $^{1}$, QI-QIANG GUO ${ }^{2}$, YANG WEI ${ }^{1}$, KAI-MING REN ${ }^{1}$, FU-SHUANG ZHENG $^{1}$, \\ JUN TANG $^{1}$, HONG-YAN ZHANG ${ }^{1}$ and JUN-GANG ZHAO ${ }^{1}$
}

${ }^{1}$ Department of The First Thoracic Surgery, Shengjing Hospital of China Medical University, Shenyang, Liaoning 110004; ${ }^{2}$ Key Laboratory of Medical Cell Biology, Ministry of Education, Institute of Translational Medicine, China Medical University, Liaoning Province Collaborative Innovation Center of Aging Related Disease Diagnosis and Treatment and Prevention, Shenyang, Liaoning 110122, P.R. China

Received April 11, 2019; Accepted September 24, 2019

DOI: $10.3892 /$ or.2019.7378

\begin{abstract}
The competing endogenous RNA (ceRNA) network is crucial for the development and progression of tumors, including non-small cell lung cancer (NSCLC). However, what type of ceRNA network regulates NSCLC has not been clarified. The present study aimed to elucidate the long non-coding RNA (lncRNA)/microRNA (miRNA)/mRNA ceRNA network in NSCLC, particularly for the significance of IncRNAs in NSCLC. NSCLC-specific differentially expressed lncRNAs, miRNAs and mRNAs in the Cancer Genome Atlas (TCGA) were analyzed and their relationship was analyzed by a ceRNA network. Their potential functions of differentially expressed mRNAs were analyzed by Gene Ontology (GO) and Kyoto Encyclopedia of Genes and Genomes (KEGG). Furthermore, the expression levels of four selected lncRNAs in TCGA were determined and their associated survival of patients was examined. In addition, the expression profiles of these four lncRNAs in 48 NSCLC specimens and cell lines, their cellular distribution and associated clinical parameters were examined. We successfully constructed a ceRNA network, including 113 lncRNAs, 12 miRNAs and 36 mRNAs differentially expressed between NSCLC and
\end{abstract}

Correspondence to: Professor Jun-Gang Zhao, Department of The First Thoracic Surgery, Shengjing Hospital of China Medical University, 36 Sanhao Street, Heping, Shenyang, Liaoning 110004, P.R. China

E-mail: zhaojg@sj-hospital.org

Abbreviations: NSCLC, non-small cell lung cancer; ceRNA, competing endogenous RNA; MREs, miRNA response elements; lncRNA, long non-coding RNA; miRNA, microRNA; GO, Gene Ontology; KEGG, Kyoto Encyclopedia of Genes and Genomes; TCGA, The Cancer Genome Atlas

Key words: TCGA, NSCLC, ceRNA network, miRNA, IncRNA, survival, clinical parameters non-tumor tissues. LINC00525, MED4-AS1, STEAP2-AS1 and SYNPR-AS1 lncRNAs were selected and validated for their association with the survival of NSCLC patients. The expression of these lncRNAs was upregulated in 48 NSCLC tissues and was varying in NSCLC cells. While LINC00525 was mainly expressed in the cytoplasm, MED4-AS1 was in both the nucleus and cytoplasm of A549 cells. In addition, the expression of LINC00525 was significantly associated with smoking history $(\mathrm{P}<0.05)$; MED4-AS1 was significantly associated with women, poor differentiation and lymph node metastasis $(\mathrm{P}<0.05)$; STEAP2-AS1 was significantly associated with women $(\mathrm{P}<0.01)$; and SYNPR-AS1 was significantly associated with women and adenocarcinoma $(\mathrm{P}<0.05)$. These lncRNAs may be valuable biomarkers for prognosis of NSCLC and the ceRNA network may provide new insights in the pathogenesis of NSCLC.

\section{Introduction}

Non-small cell lung cancer (NSCLC) is a common lung cancer with a high incidence. In the past decades, although great advances have been made in NSCLC diagnosis, surgical resection, targeted therapies, radiotherapies, immunotherapies and chemotherapies (1-5) the 5-year overall survival and recurrence rate of NSCLC patients is still not satisfactory. The poor outcomes may stem from the few biomarkers available for precise prognosis of NSCLC and incompletely understanding the pathogenesis of NSCLC. Therefore, identification of new prognostic markers and understanding of the molecular mechanisms underlying the pathogenesis of NSCLC would be of great significance in the management of NSCLC patients.

Long non-coding RNAs (lncRNAs), a class of non-coding RNAs with $>200$ nucleotides in length (6). are important regulators of many biological activities, such as transcription, RNA protein modification, and RNA interaction (7). lncRNAs demonstrate their own characteristics: i) The sequence is less conserved, only $\sim 12 \%$ of lncRNAs can be found in other organisms other than humans, indicating their specificity in humans; ii) some lncRNAs have a unique subcellular location 
and may have a novel subcellular composition; iii) lncRNAs can regulate gene expression from chromatin remodeling, transcriptional regulation and post-transcriptional processing; iv) IncRNAs can be recognized by other complementary nucleic acids and direct the protein to specific sequence sites, which makes lncRNAs more abundant in cancers. Previous studies have revealed that altered expression of IncRNAs is associated with the development and progression of human malignant tumors, including lung and liver cancer, osteosarcoma, glioblastoma and as well as other types of cancer (8-11). Furthermore, lncRNAs can act as oncogenes or tumor suppressor genes, modulating the progression of NSCLC and affecting the overall survival (OS) of NSCLC patients $(12,13)$.

Multiple RNA transcripts, such as mRNAs, lncRNAs, pseudogenes, and circular RNAs, can act as competing endogenous RNAs (ceRNAs) to mutually regulate their function by competitive binding of miRNA response elements (MREs) (14). Abnormal expression of any transcript may cause a failure to control a regulatory network, ultimately leading to the development and progression of cancer (15). This type of regulatory network is widely found in various cancer diseases, such as hepatocellular carcinoma, pheochromocytoma, and ovarian cancer (16-18). Previous studies have revealed that upregulated HOTAIR expression was associated with metastasis and poor prognosis of NSCLC, and HOTAIR could promote the proliferation, survival, invasion, metastasis, and drug resistance of NSCLC cells (19) while MALAT1 altered the expression of metastasis-associated genes in NSCLC (20). However, little is known on what type of ceRNA network regulates the progression of NSCLC.

In the present study, the differentially expressed lncRNAs, miRNAs and related mRNAs in NSCLC were extracted from The Cancer Genome Atlas (TCGA) to construct a ceRNA network. Subsequently, the expression of four selected IncRNAs, their subcellular localization, and associated clinical parameters in NSCLC tissues were analyzed. The present findings indicated that these lncRNAs may be valuable biomarkers for prognosis and the ceRNA network may provide new insights into the pathogenesis of NSCLC.

\section{Materials and methods}

RNA sequencing data and analysis in TCGA. Differentially expressed RNAs were screened from RNA-seq data and miRNA-seq data in TCGA (cancergenome.nih.gov) separately, since lncRNAs and mRNAs were included in the RNA-seq database and miRNAs were included in the miRNA-seq database (21). Then, the data of RNA expression in NSCLC were extracted from these two databases and normalized by 'DESeq2' and 'edgeR' package. The obtained P-values were corrected by false discovery rate (FDR). Differentially expressed mRNAs, lncRNAs and miRNAs were considered when the RNA transcript between NSCLC and non-tumor tissues reached a P-value of $<0.01$, FDR $<0.01$ and $\log F C$ (fold change) $>2$. Their expression levels were expressed as Fragments Per Kilobase Million (FPKM).

Construction of a ceRNA network. A ceRNA network was established by three steps: i) By miRcode matching, individual miRNAs that interacted with the differentially expressed lncRNAs and overlapped with the differentially expressed miRNAs were used for establishment of the lncRNA/miRNA relationship; ii) the mRNAs targeted by miRNAs in the IncRNA/miRNA network were predicted by miRDB (http://mirdb.org/), miRTarBase (http://mirtarbase. mbc.nctu.edu.tw/php/index.php), and TargetScan databases (http://www.targetscan.org/vert_72/), and they were overlapped with the previously selected differentially expressed mRNAs to construct the miRNA-mRNA relationship network; iii) finally, the ceRNA network was constructed, based on the aforementioned two relationship networks using the 'ggalluvial' $\mathrm{R}$ package.

Prognostic analysis of lncRNAs in the network. Individual subjects in the TCGA database were stratified, according to the levels of specific lncRNAs, and their survival data were extracted. The survival difference of subjects with varying levels of individual lncRNAs in the ceRNA network was analyzed using 'survminer' R package and 'surv_cutpoint' function.

Bioinformatics. The potential functions and pathway enrichments of the differentially expressed genes identified in the ceRNA network were analyzed by gene ontology (GO) (http://geneontology.org/) (22) and Kyoto Encyclopedia of Genes and Genomes (KEGG) (https://www.kegg.jp/) (23) using the $\mathrm{R}$ language, based on a $\mathrm{P}$-value of $<0.05$. The diagnostic values of these differentially expressed RNAs were analyzed by receiver operating characteristic (ROC) curve.

Clinical specimens. Surgical NSCLC specimens were obtained from 48 individual patients (23 males and 25 females; age range, 45-81 years), who underwent NSCLC surgery at the Affiliated Shengjing Hospital, China Medical University, Shenyang, China from May 2017 to July 2018. All samples were frozen at $-80^{\circ} \mathrm{C}$ immediately after excision during surgery. The NSCLC specimens were staged pathologically by the TNM of the UICC (Union for International Cancer Control) (24). The experimental protocol was approved by the Shengjing Hospital Ethics Committee (2018PS170K) and written informed consent was obtained from all patients.

Cell culture. Human non-tumor lung epithelial BEAS-2B cells, 293 cells, NSCLC A549, NCI-H460, NCI-H1299 and NCI-H292 cells (<25 passages) were obtained from the Type Culture Collection of the Chinese Academy of Sciences (Shanghai, China). BEAS-2B and 293 cells were cultured in Dulbecco's modified Eagle's medium (DMEM)/F12 containing $10 \%$ heat-inactivated fetal bovine serum (FBS), $100 \mathrm{IU} / \mathrm{ml}$ penicillin and $100 \mu \mathrm{g} / \mathrm{ml}$ streptomycin at $37^{\circ} \mathrm{C}$ in $5 \%$ $\mathrm{CO}_{2}$. NSCLC cells were maintained in $10 \%$ FBS RPMI-1640 medium.

RNA extraction and quantitative RT-PCR. Total RNA was extracted from individual specimens and cells using TRIzol reagent and reversely-transcribed into cDNA using HisScript ${ }^{\mathrm{TM}}$ QRT SuperMix (Vazyme Biotech Co., Ltd., Nanjing, China). The relative levels of RNA transcripts to the control were determined by qRT-PCR on Agilent Technologies Stratagene 


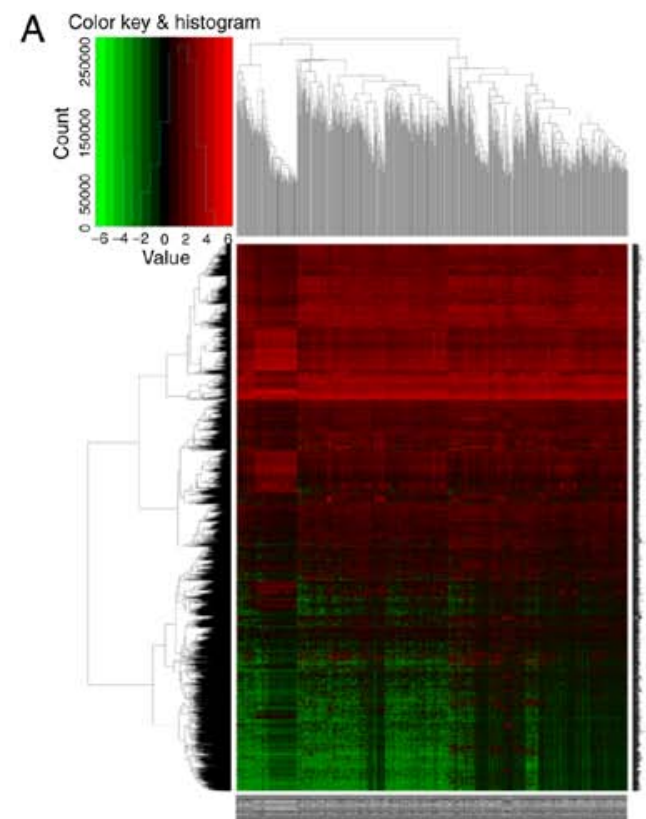

Heatmap-mRNA

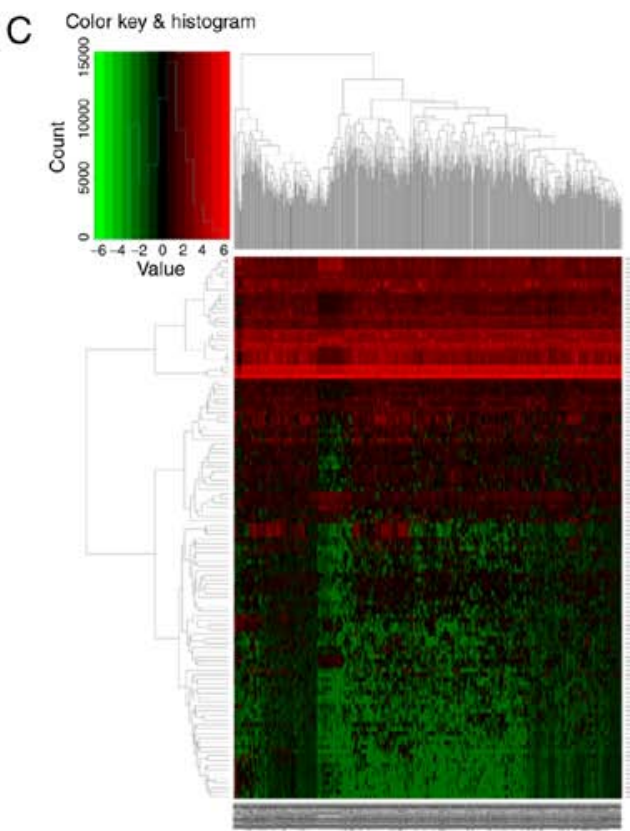

Heatmap-miRNA

E

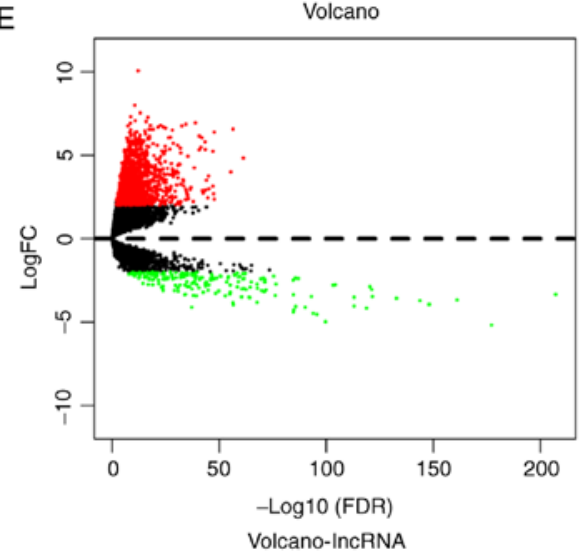

B

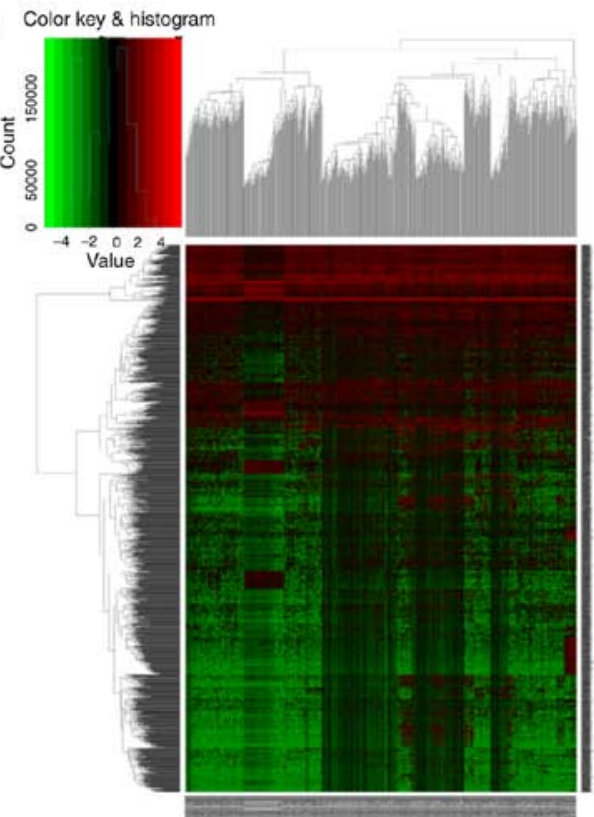

Heatmap-IncRNA

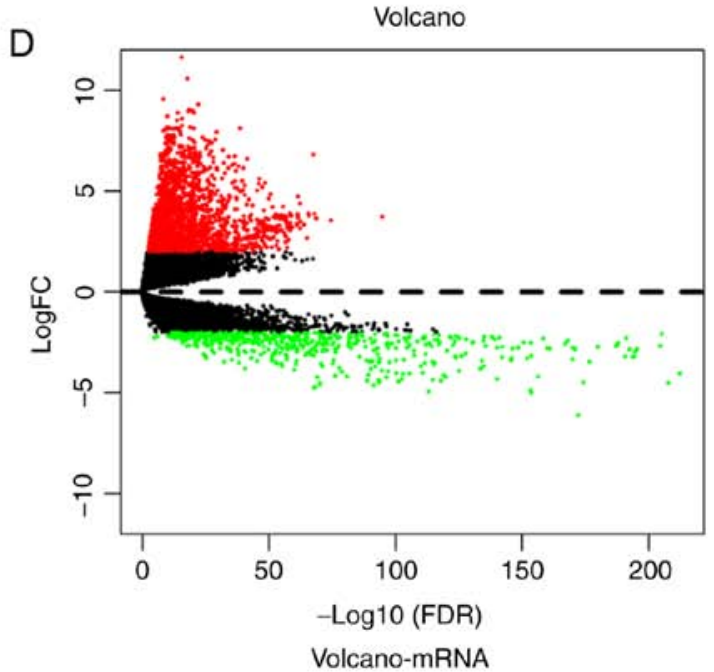

F

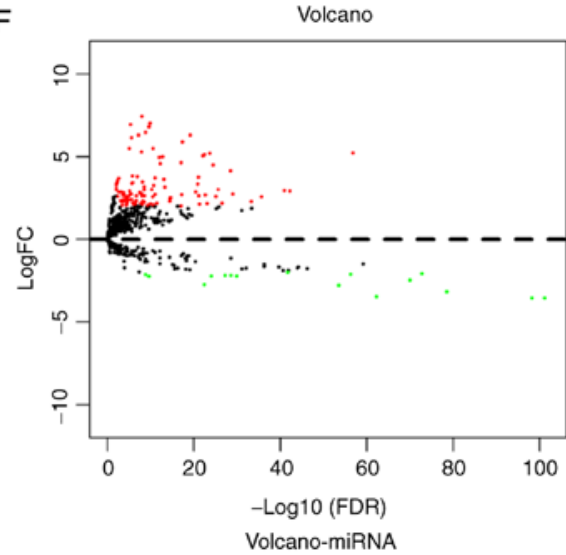

Figure 1. Analysis of differentially expressed RNAs in NSCLC tissues by heatmaps and volcano maps. The expression levels of mRNAs, lncRNAs and miRNAs in NSCLC and adjacent non-tumor tissues was extracted from TCGA and analyzed by (A-C) heatmap and (D-F) volcano map, respectively. Data are the distribution of individual NSCLC patients. The green dots, downregulated RNAs; the red dots, upregulated RNAs. NSCLC, non-small cell lung cancer; lncRNAs, long non-coding RNAs; miRNAs, microRNAs; TCGA, The Cancer Genome Atlas. 


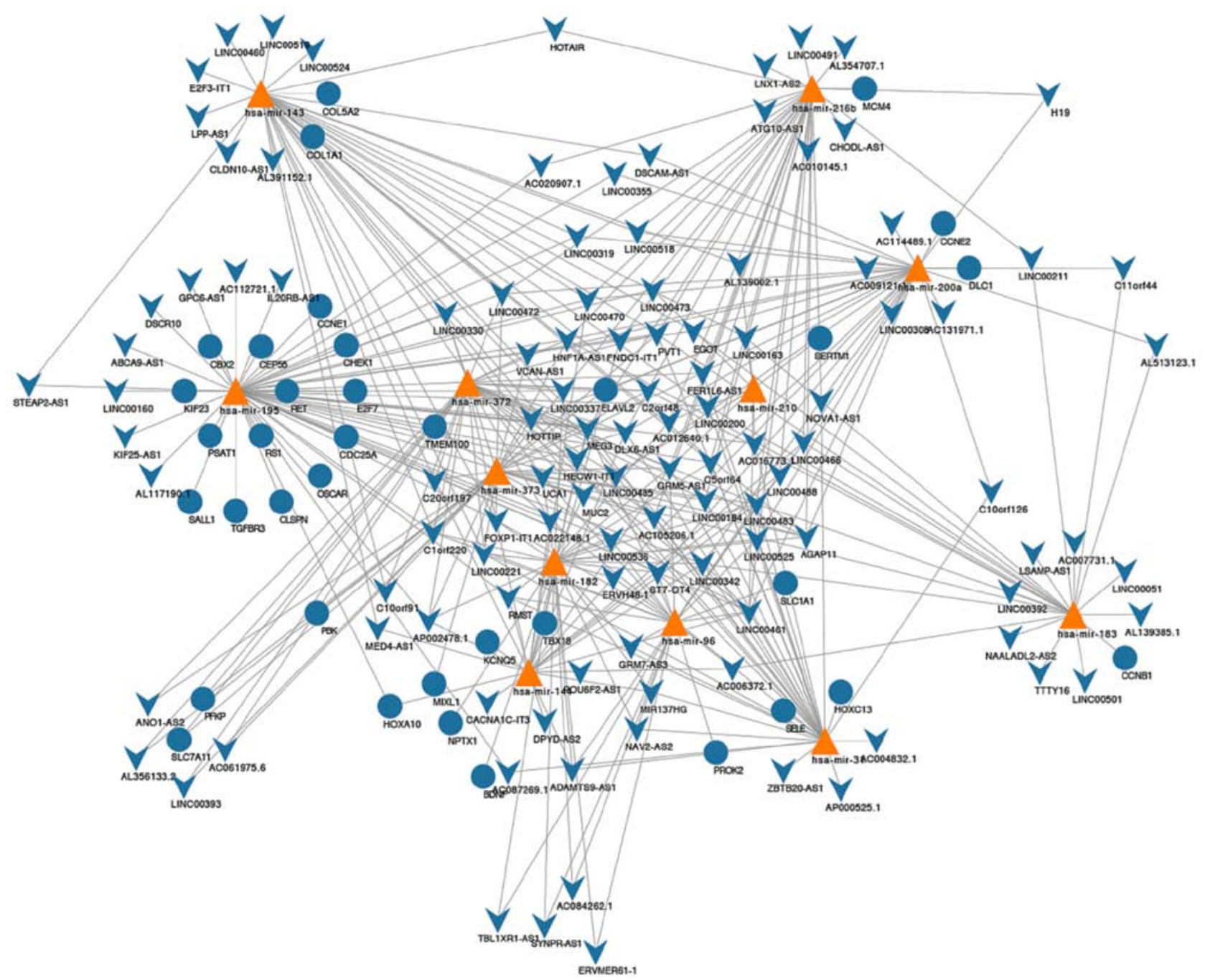

Figure 2. The ceRNA network consists of 113 differentially expressed lncRNAs, 12 miRNAs, and 36 mRNAs. ceRNA, competing endogenous RNA; lncRNAs, long non-coding RNAs; miRNAs, microRNAs.

Mx3000P using ChamQ ${ }^{\text {TM }}$ Universal SYBR qPCR Master Mix (Vazyme Biotech Co., Ltd.) and specific primers are presented in Table SI. The data were normalized and analyzed by $2^{-\Delta \Delta \mathrm{Cq}}$ method (25).

Subcellular fractionation. The cells were harvested and after being washed, and then they were treated with $500 \mu \mathrm{l}$ of cell disruption buffer (PARIS kit; cat. no. AM1921; Invitrogen; Thermo fisher Scientific, Inc.) on ice for $10 \mathrm{~min}$, followed by centrifugation at $500 \mathrm{x}$ g. Their supernatants were collected as the cytoplasmic samples. The pellets were washed and solved in an equal volume of nuclear lysate buffer, followed by centrifugation at $500 \mathrm{x}$. The supernatants were used as the nuclear samples. Subsequently, the RNAs in the nuclear and cytoplasmic samples were extracted and subjected to qRT-PCR using primers presented in Table SI.

Statistical analysis. Data are expressed as the mean \pm SD. Difference between two groups was analyzed by unpaired Student's t-test. Difference of multiple comparisons was analyzed by ANOVA (parametric) followed by Dunnett's post-test. The category data were analyzed by Chi-square test. All statistical analyses were performed using SPSS 22.0 software (IBM Corp.) and GraphPad Prism version 7.0 (GraphPad Software, Inc.). A two-tailed P-value of $<0.05$ was considered to indicate a statistically significant difference.

\section{Results}

Screening of differentially expressed RNAs of NSCLC in $T C G A$. To screen differentially expressed RNAs, RNA-seq data of 535 NSCLC and 59 paracancerous lung samples and miRNA-seq data of 521 NSCLC and 46 paracancerous lung samples from the TCGA database were extracted. Based on statistical significance of $\mathrm{P}<0.01, \mathrm{FDR}<0.01$ and $\mid \log \mathrm{FCl}>2$, these data were analyzed by heatmaps and volcanoes (Fig. 1). There were 2,502 differentially expressed mRNAs (Fig. 1A), of which, 1,975 were upregulated and 527 downregulated (Fig. 1D). Furthermore, there were 1,685 differentially expressed lncRNAs (Fig. 1B), of which, 1,486 were upregulated and 199 downregulated (Fig. 1E). Moreover, there were 120 differentially expressed miRNAs (Fig. 1C), of which, 104 were upregulated and 16 downregulated (Fig. 1F).

Construction of ceRNA network. The miRcode matching indicated that $144 \mathrm{lncRNAs}$ and $22 \mathrm{miRNAs}$ effectively 
A

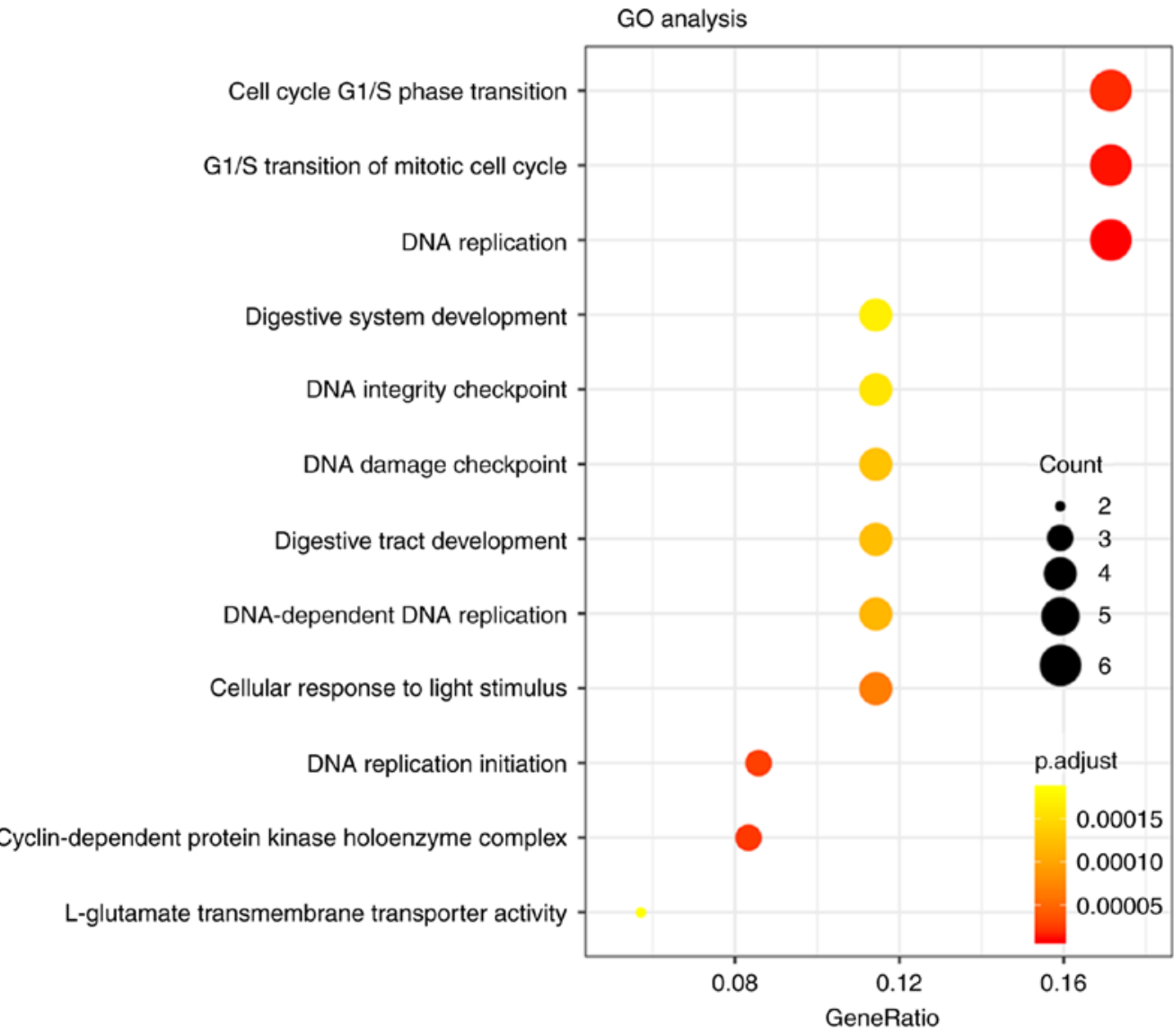

B KEGG analysis

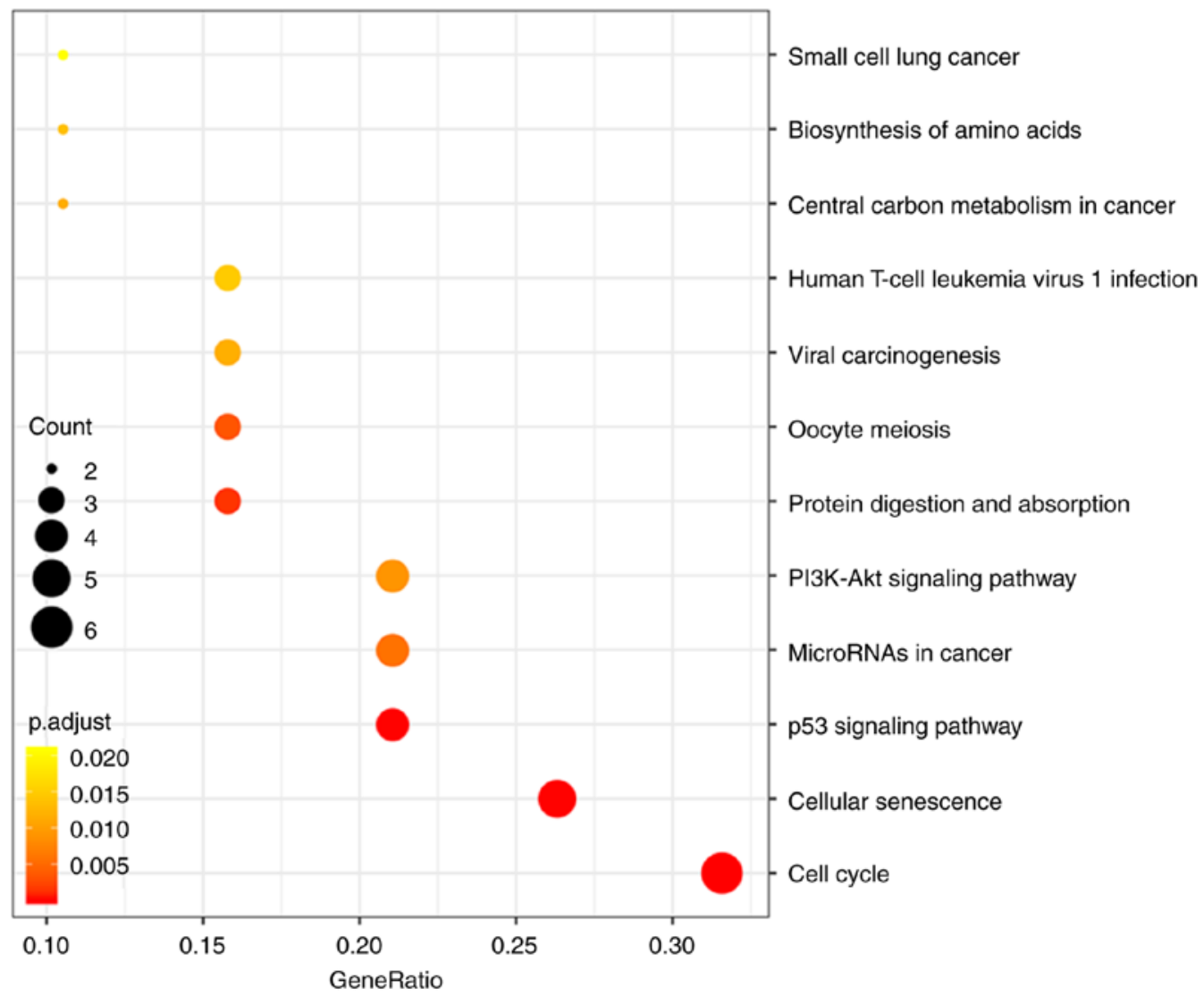

Figure 3. Potential functions of the differentially expressed lncRNAs analyzed by GO and KEGG analyses. The potential functions of the differentially expressed lncRNAs in NSCLC were analyzed by GO and KEGG analyses. (A) The GO analysis of biological processes, cellular components, molecular functions. (B) The KEGG analysis of potential pathways. Data are expressed as the enrichment values of lncRNAs for the specific function. lncRNAs, long non-coding RNAs; GO, gene ontology; KEGG, Kyoto Encyclopedia of Genes and Genomes; NSCLC, non-small cell lung cancer. 

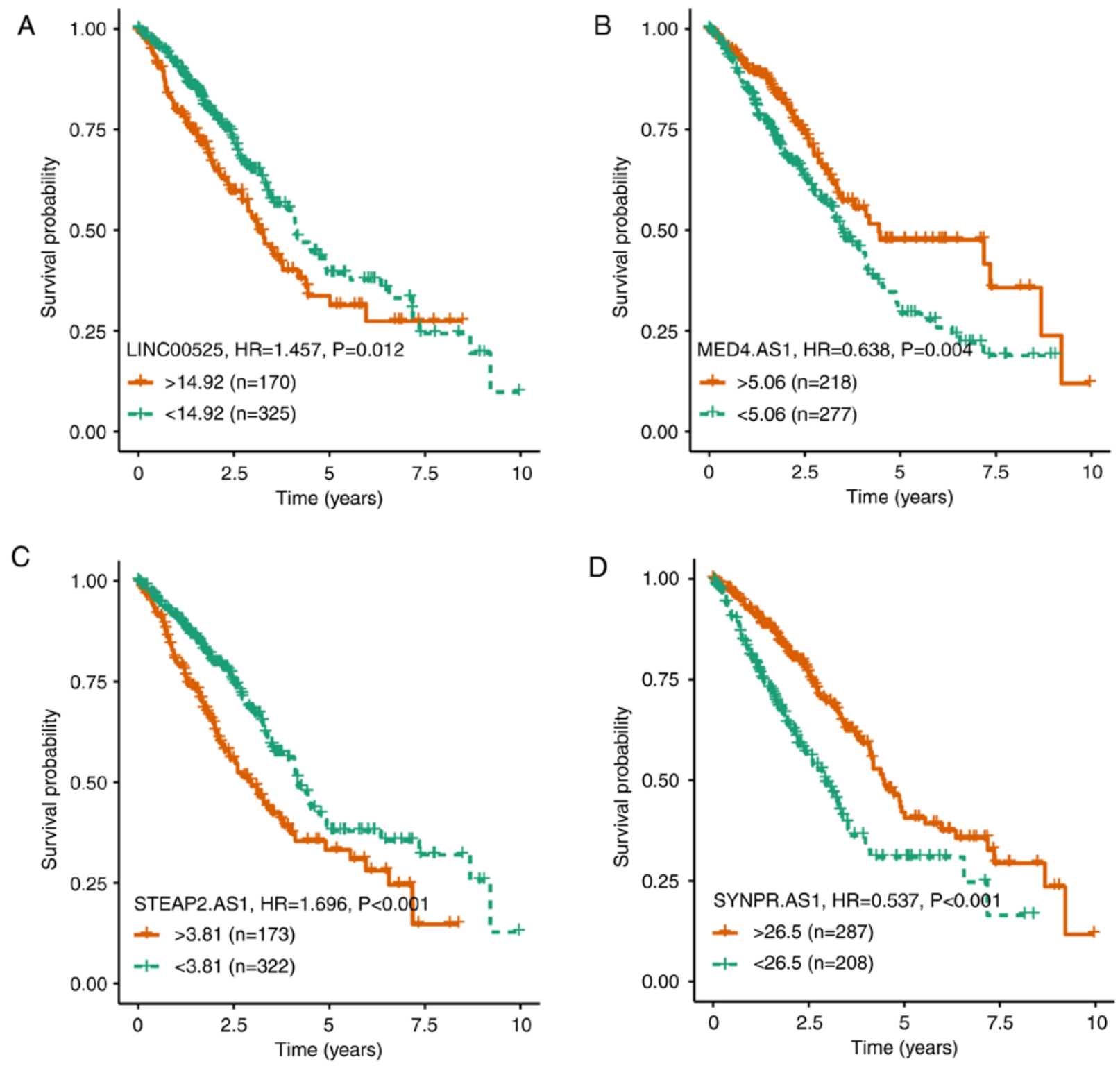

Figure 4. Kaplan-Meier analysis of the survival of patients with varying levels of lncRNA expression in NSCLC. Individual NSCLC patients were stratified, based on the cut-off value of each lncRNA and their overall survival was estimated by the Kaplan-Meier analysis. The difference between the groups was analyzed by log-rank test. (A and C) The upregulated LINC00525 and STEAP2-AS1 expression was associated with a shorter survival of NSCLC patients. (B and D) The upregulated MED4-AS1 and SYNPR-AS1 expression was associated with a longer survival of NSCLC patients. IncRNA, long non-coding RNA; NSCLC, non-small cell lung cancer.

generated 570 pairs of associations (Table SII). Furthermore, using the miRDB, miRTarBase and TargetScan databases, we predicted that these 22 miNRAs targeted 722 mRNAs. After overlapping the 2,502 differentially expressed mRNAs with 722 mRNAs, 12 miRNAs formed 44 miRNA-mRNA association pairs (Table SIII). Accordingly, a ceRNA network was constructed and contained 113 DElncRNAs, 12 DEmiRNAs, and 36 DEmRNAs (Fig. 2). Further analysis of the network revealed that it contained 161 nodes and 372 edges. The degrees of the network were detailed in Table SIV.

GO and KEGG pathway analyses. The potential biological functions of mRNA in ceRNA networks were analyzed by GO and KEGG. The results revealed that mRNAs in the ceRNA network were mainly involved in the cell cycle G1/S phase transition and DNA replication (Fig. 3A) and participated in the processes of the cell cycle, cellular senescence and p53 signaling (Fig. 3B).

Related lncRNAs in the ceRNA network. After stratification of those subjects, based on the differentially expressed lncRNAs, 103 out of 113 lncRNAs in the network were significantly associated with prognosis in this population (Table SIII). Since LINC00525, MED4-AS1, STEAP2-AS1, SYNPR-AS1 were novel lncRNAs in NSCLC and their differential fold and P-values were the most significant (Table SV), their functional association with survival was further analyzed (Fig. 4). The higher levels of LINC00525 or STEAP2-AS1 were significantly associated with a shorter survival of NSCLC patients while higher levels of MED4-AS1 or SYNPR-AS1 were significantly associated with a longer survival of NSCLC 
A

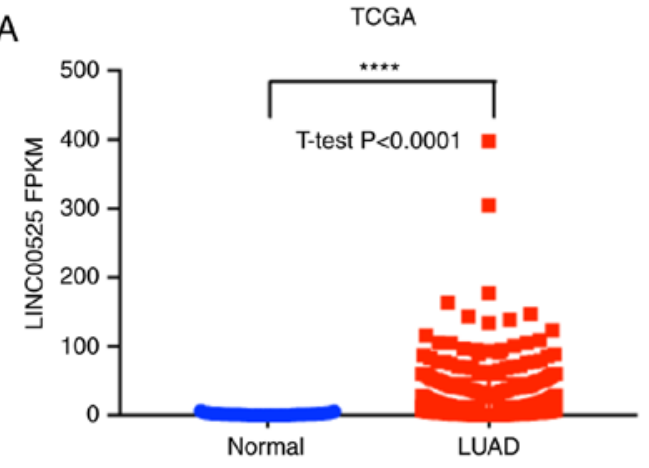

C

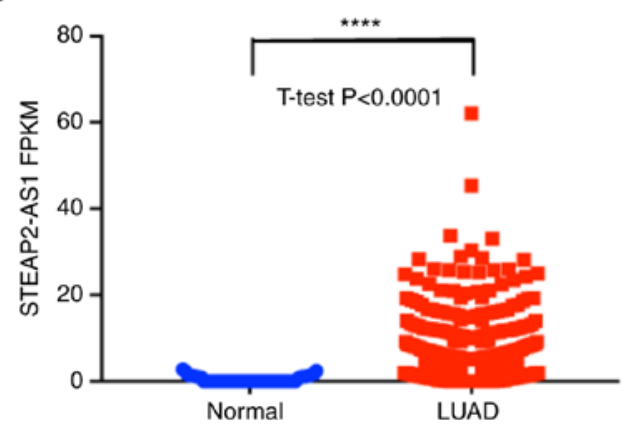

E

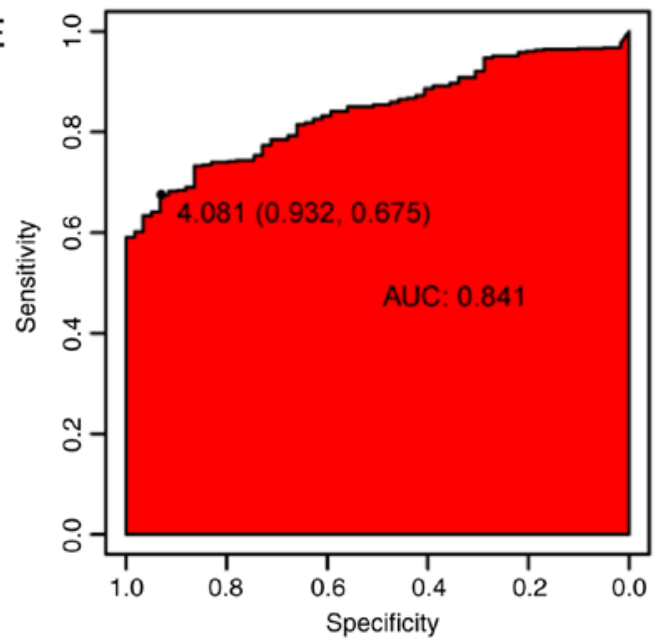

G

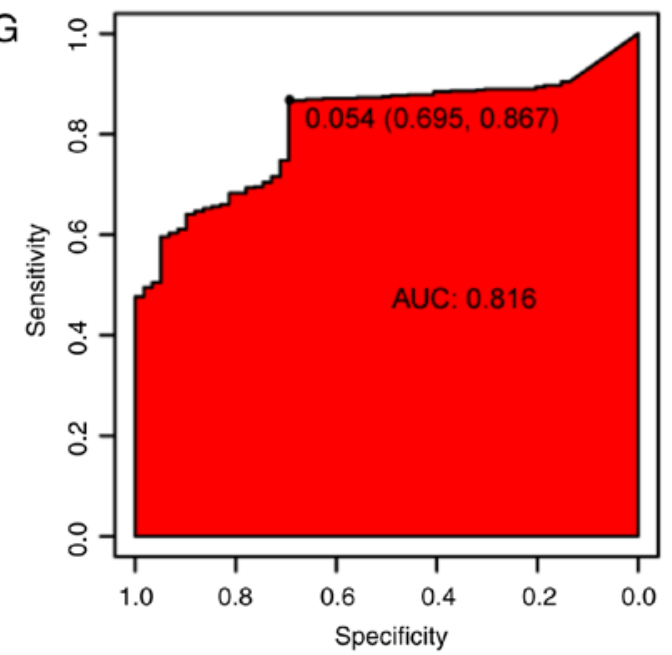

B

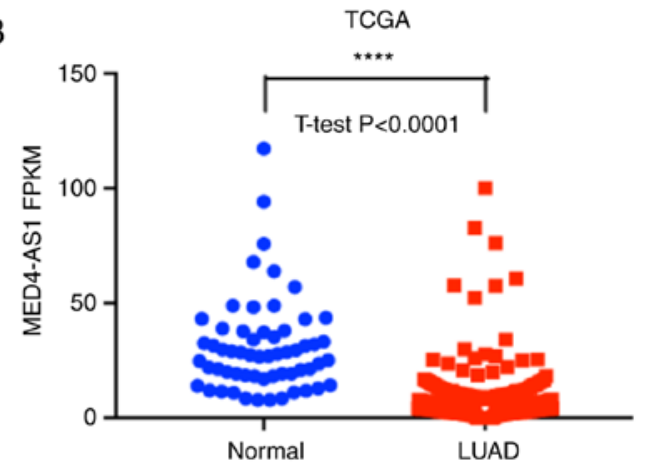

D

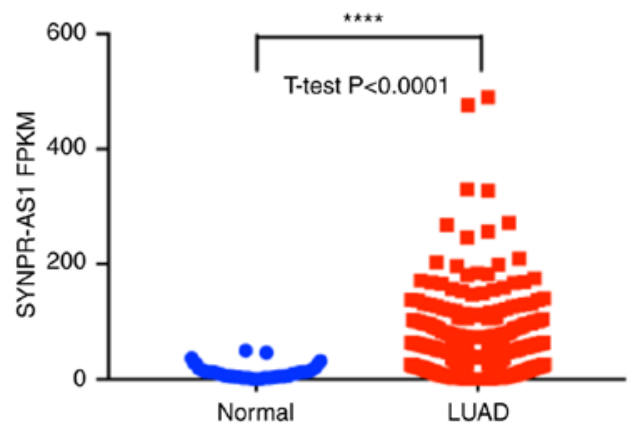

$\mathrm{F}$

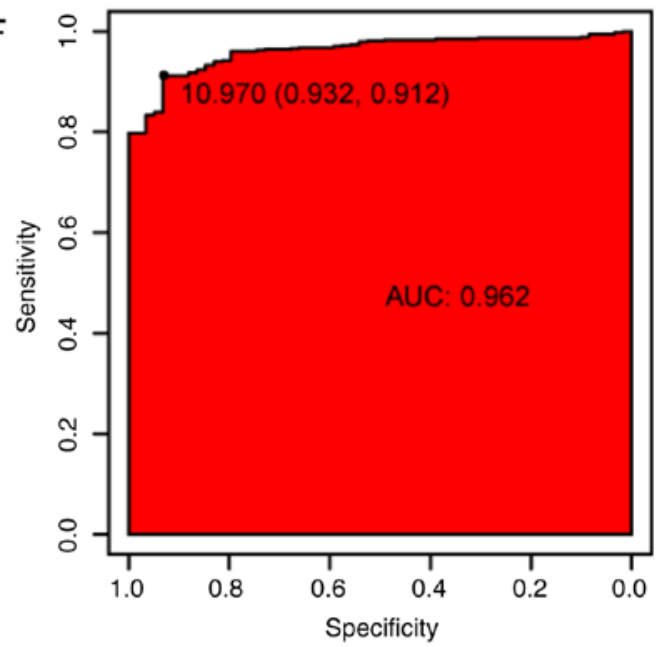

$\mathrm{H}$

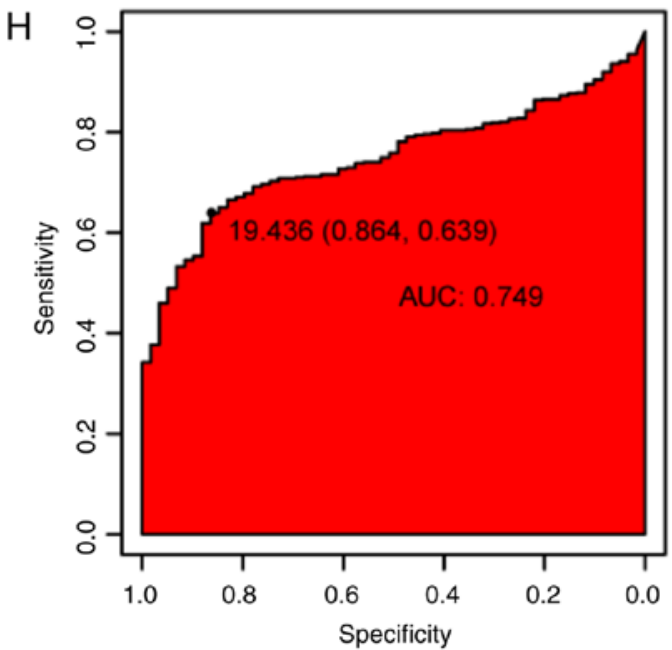

Figure 5. Expression levels of four selected lncRNAs. The expression levels of four selected lncRNAs in NSCLC and their adjacent non-tumor tissues in TCGA were compared and the potential diagnostic values of these IncRNAs were determined by ROC analysis. Data are expressed as individual values and the AUC values of individual lncRNAs. (A-D) Scatter plots of the expression of individual lncRNAs. (E-H) The ROC analysis of individual lncRNAs. IncRNAs, long non-coding RNAs; NSCLC, non-small cell lung cancer; TCGA, The Cancer Genome Atlas; ROC, receiver operaring characteristic; AUC, area under the curve. ${ }^{* * * * *} \mathrm{P}<0.0001$. 
A

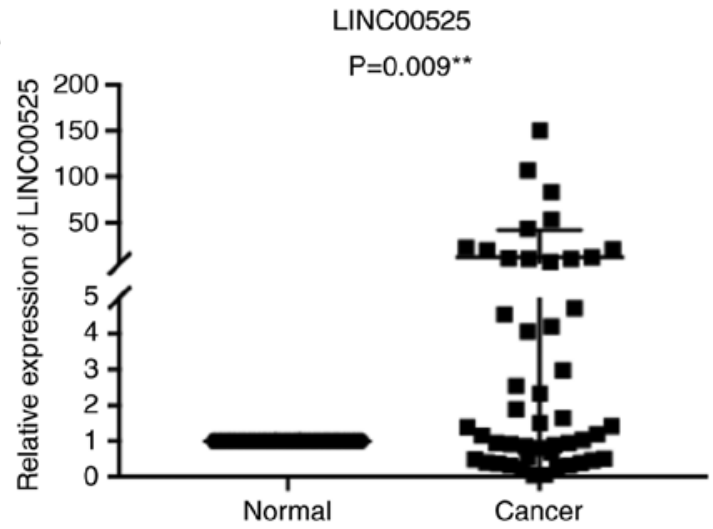

C

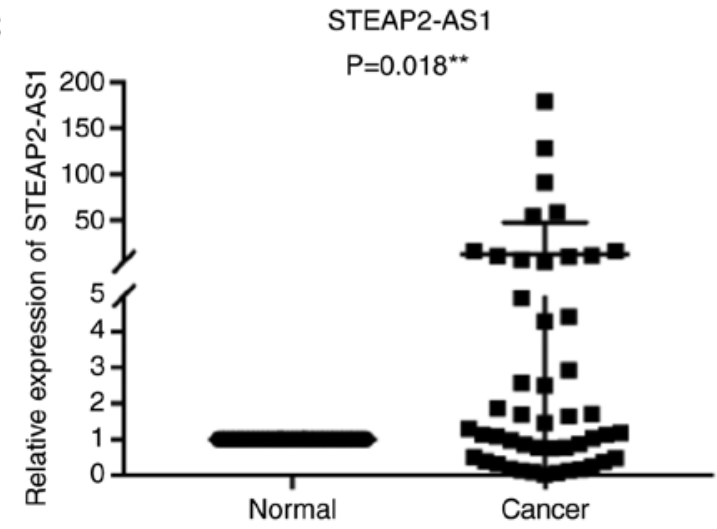

E

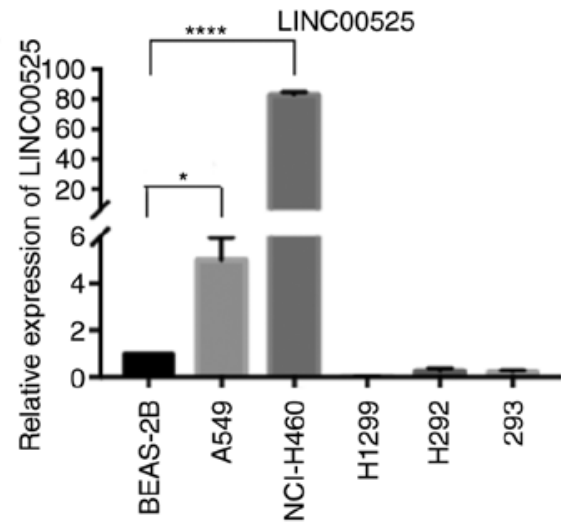

G

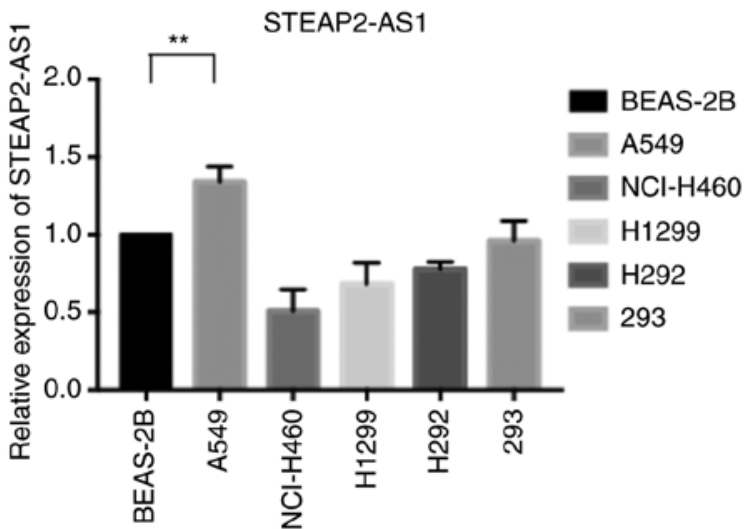

B

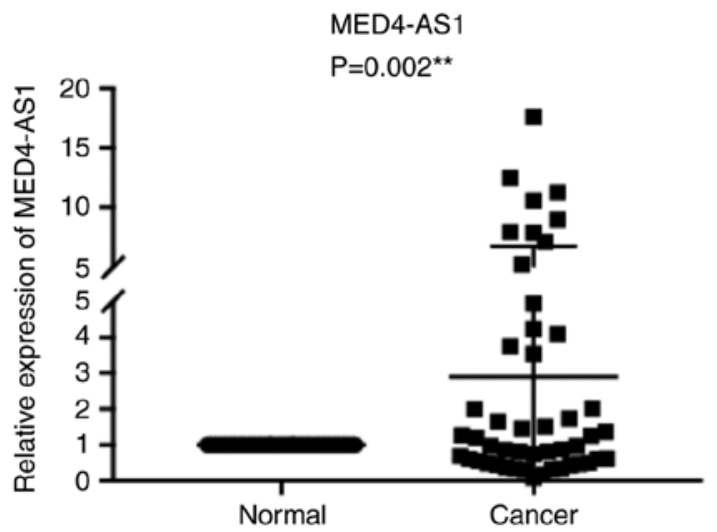

D

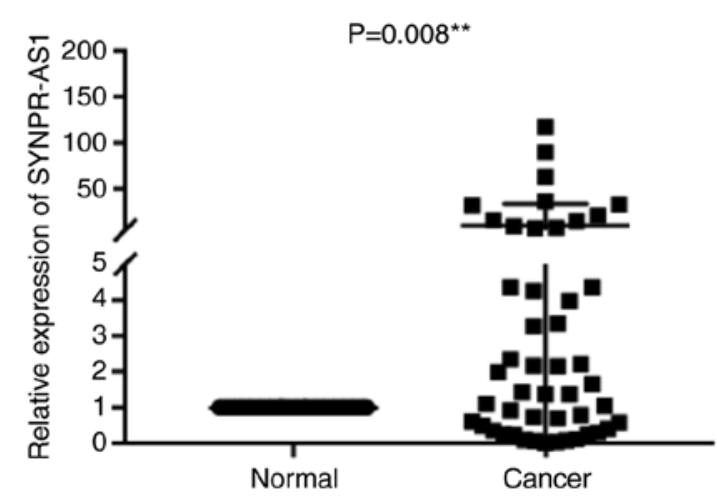

$\mathrm{F}$

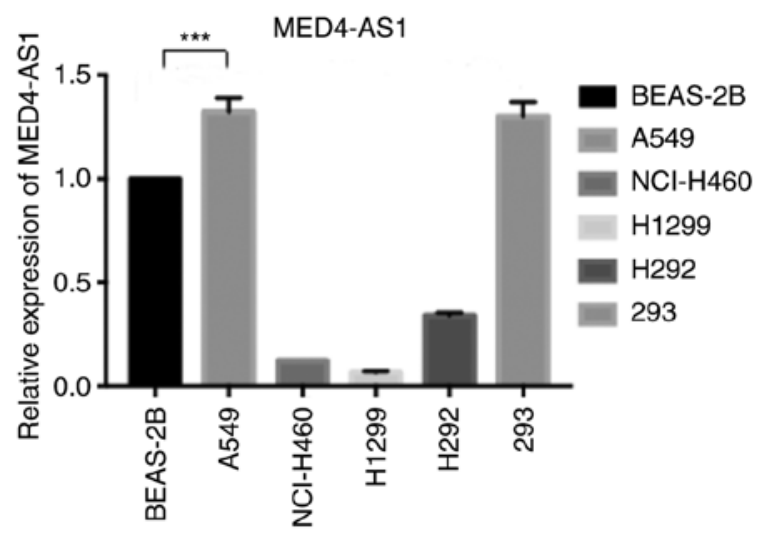

$\mathrm{H}$

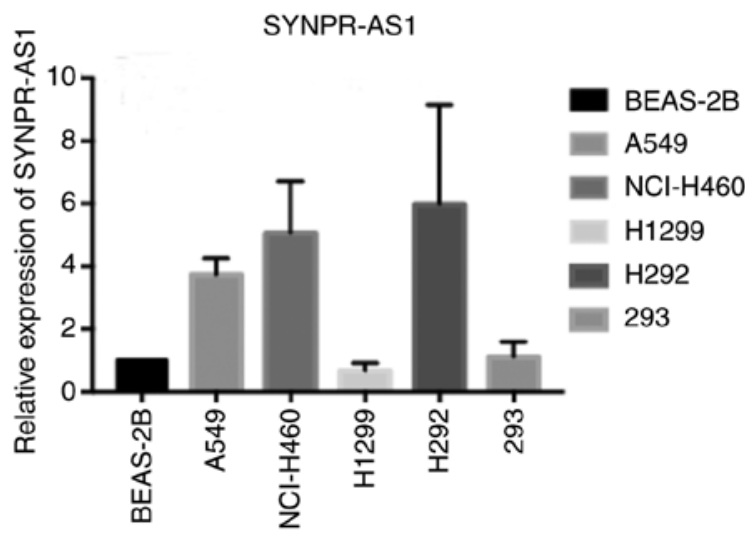

Figure 6. Expression levels of four selected lncRNAs in 48 NSCLC and their adjacent non-tumor tissues and different cell lines. The expression levels of individual lncRNAs in 48 NSCLC and their adjacent non-tumor tissues and different cell lines were determined by quantitative RT-PCR. Data are expressed as the mean values of individual specimens or the mean value \pm SD of each group of cells from three separate experiments. (A-D) The differential expression of individual lncRNAs in 48 pairs of NSCLC and their adjacent non-tumor tissues. The statistical test was performed using unpaired Student's t-test. (E-H) The expression levels of individual lncRNAs in the indicated cells. The statistical test was performed using ANOVA (parametric) test. lncRNAs, long non-coding RNAs; NSCLC, non-small cell lung cancer. ${ }^{*} \mathrm{P}<0.05,{ }^{* *} \mathrm{P}<0.01,{ }^{* * * *} \mathrm{P}<0.001,{ }^{* * * * *} \mathrm{P}<0.0001$. 
Table I. The association between LINC00525 expression and the clinical characteristics of NSCLC patients.

\begin{tabular}{|c|c|c|c|c|}
\hline \multirow[b]{2}{*}{ Characteristics } & \multirow[b]{2}{*}{$\mathrm{N}$} & \multicolumn{3}{|c|}{ Relative LINC00525 expression } \\
\hline & & Low & High & P-value \\
\hline \multicolumn{5}{|l|}{ Age (years) } \\
\hline$>65$ & 9 & 5 & 4 & 0.712 \\
\hline$\leq 65$ & 39 & 19 & 20 & \\
\hline \multicolumn{5}{|l|}{ Sex } \\
\hline Male & 23 & 13 & 10 & 0.386 \\
\hline Female & 25 & 11 & 14 & \\
\hline \multicolumn{5}{|l|}{ Differentiation } \\
\hline Well, moderate & 36 & 17 & 19 & 0.505 \\
\hline Poor & 12 & 7 & 5 & \\
\hline \multicolumn{5}{|c|}{ Tumor size (maximum diameter) } \\
\hline$>3 \mathrm{~cm}$ & 22 & 10 & 12 & 0.562 \\
\hline$\leq 3 \mathrm{~cm}$ & 26 & 14 & 12 & \\
\hline \multicolumn{5}{|l|}{ Histological tumor type } \\
\hline Squamous cell carcinoma & 17 & 9 & 8 & 0.763 \\
\hline Adenocarcinoma & 31 & 15 & 16 & \\
\hline \multicolumn{5}{|l|}{ Smoking history } \\
\hline Smokers & 20 & 6 & 14 & $0.036^{\mathrm{a}}$ \\
\hline Never smoked & 28 & 17 & 11 & \\
\hline \multicolumn{5}{|l|}{ Lymph node metastasis } \\
\hline Positive & 21 & 9 & 12 & 0.383 \\
\hline Negative & 27 & 15 & 12 & \\
\hline \multicolumn{5}{|l|}{ TNM stage } \\
\hline Stage I & 20 & 12 & 8 & 0.242 \\
\hline Stages II, III or IV & 28 & 12 & 16 & \\
\hline
\end{tabular}

${ }^{\mathrm{a}} \mathrm{P}<0.05$. Data were analyzed by Chi-square test. The high and low groups were divided by the median expression value of LINC00525 (1.405). NSCLC, non-small cell lung cancer.
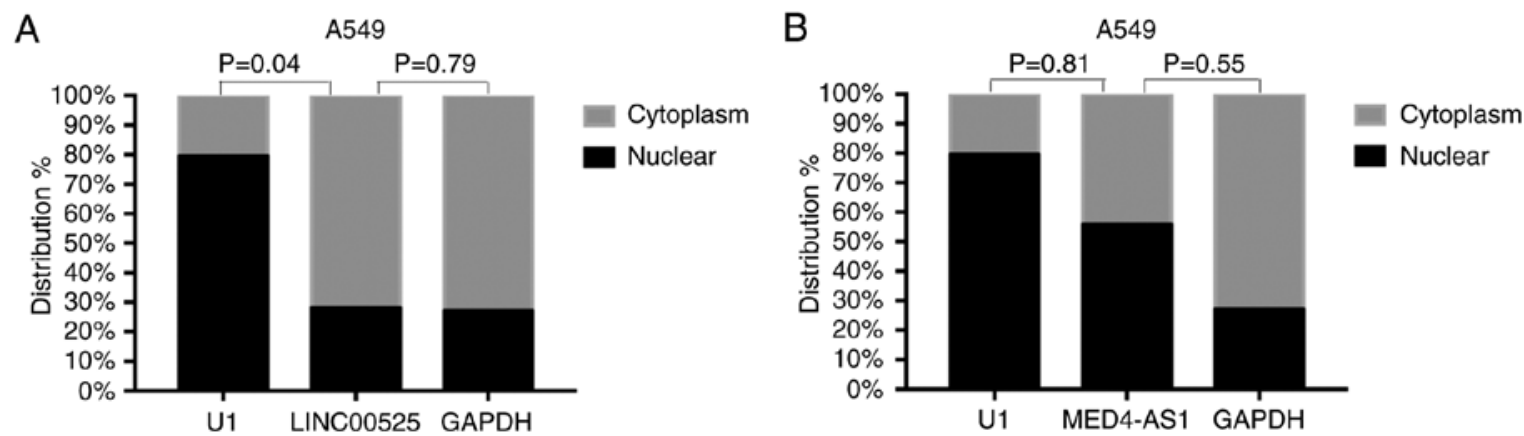

Figure 7. Distribution of LINC00525 and MED4-AS1 in A549 cells. The nucleus and cytoplasm of A549 cells were extracted and the levels of LINC00525 and MED4-AS1 in these cellular compartments were determined by quantitative RT-PCR. Data are presented as the mean values of individual lncRNAs in each compartment of A549 cells from three independent experiments. (A and B) The nuclear and cytoplasmic distribution of LINC00525 and MED4-AS1 in A549 cells. U1 snRNA, nuclear control; GAPDH, cytoplasmic control. The statistical test was performed using Chi-square test. lncRNAs, long non-coding RNAs.

patients. Hence, these IncRNAs had opposite functions in regulating the development and progression of NSCLC.

Expression and ROC curve analysis of four IncRNAs in TCGA. To quantify IncRNA expression, four lncRNAs in tumor and adjacent non-tumor tissues of individual subjects in TCGA were quantified as FPKM values. The FPKM values of LINC00525, STEAP2-AS1 and SYNPR-AS1 in NSCLC tissues were significantly greater while the FPKM values of MED4-AS1 in NSCLC tissues were significantly 
Table II. The association between MED4-AS1 expression and the clinical characteristics of NSCLC patients.

\begin{tabular}{|c|c|c|c|c|c|}
\hline \multirow[b]{2}{*}{ Characteristics } & \multirow[b]{2}{*}{$\mathrm{N}$} & \multicolumn{4}{|c|}{ Relative MED4-AS1 expression } \\
\hline & & Low & High & P-value & Adj.P-value \\
\hline \multicolumn{6}{|l|}{ Age (years) } \\
\hline$>65$ & 11 & 6 & 5 & 0.731 & 0.708 \\
\hline$\leq 65$ & 37 & 18 & 19 & & \\
\hline \multicolumn{6}{|l|}{ Sex } \\
\hline Male & 22 & 15 & 7 & $0.020^{\mathrm{a}}$ & \\
\hline Female & 26 & 9 & 17 & & \\
\hline \multicolumn{6}{|l|}{ Differentiation } \\
\hline Well, moderate & 36 & 21 & 15 & $0.046^{\mathrm{a}}$ & 0.055 \\
\hline Poor & 12 & 3 & 9 & & \\
\hline \multicolumn{6}{|c|}{ Tumor size (maximum diameter) } \\
\hline$>3 \mathrm{~cm}$ & 22 & 8 & 14 & 0.141 & 0.109 \\
\hline$\leq 3 \mathrm{~cm}$ & 26 & 15 & 11 & & \\
\hline \multicolumn{6}{|l|}{ Histological tumor type } \\
\hline Squamous cell carcinoma & 16 & 8 & 8 & 0.999 & 0.097 \\
\hline Adenocarcinoma & 32 & 16 & 16 & & \\
\hline \multicolumn{6}{|l|}{ Smoking history } \\
\hline Smokers & 19 & 12 & 7 & 0.14 & 0.477 \\
\hline Never smoked & 29 & 12 & 17 & & \\
\hline \multicolumn{6}{|l|}{ Lymph node metastasis } \\
\hline Positive & 23 & 8 & 15 & $0.043^{\mathrm{a}}$ & 0.07 \\
\hline Negative & 25 & 16 & 9 & & \\
\hline \multicolumn{6}{|l|}{ TNM stage } \\
\hline Stage I & 19 & 12 & 7 & 0.14 & 0.596 \\
\hline Stages II, III or IV & 29 & 12 & 17 & & \\
\hline
\end{tabular}

${ }^{a} \mathrm{P}<0.05$. Data were analyzed by Chi-square test. The high and low groups were divided by the median expression value of MED4-AS1 (1.085). NSCLC, non-small cell lung cancer.

less than that in the adjacent non-tumor tissues (Fig. 5A-D). Further ROC analysis revealed that the area under the curve (AUC) values of LINC00525, MED4-AS1, STEAP2-AS1, and SYNPR-AS1 were 0.841, 0.962, 0.816, and 0.749, respectively.

Validation of four lncRNAs in NSCLC samples and cells. To clarify the clinical significance of these four lncRNAs, 48 pairs of NSCLC and adjacent tissue specimens were collected. The relative expression levels of four lncRNAs in NSCLC and adjacent tissues were determined by qRT-PCR. The relative levels of four lncRNA transcripts in NSCLC tissues were significantly higher than that in the adjacent tissues (Fig. 6A-D; P<0.05). Analyses of different cell lines indicated various expression levels of these four lncRNAs (Fig. 6E-H). In comparison with that in non-tumor BEAS-2B cells, LINC00525, MED4-AS1 and STEAP2-AS1 were significantly upregulated in A549 cells. Significantly upregulated LINC00525 expression was also detected in NCI-H460 cells. SYNPR-AS1 revealed no significant difference between groups. Further analysis revealed that LINC00525 was mainly expressed in the cytoplasm while MED4-AS1 was detected in both the nucleus and cytoplasm of A549 cells (Fig. 7A and B).

Higher expression levels of four lncRNAs are associated with clinical characteristics. Finally, we analyzed the potential association between higher expression levels of individual lncRNAs and clinical parameters in 48 NSCLC patients. Notably, higher expression levels of LINC00525 were significantly associated with smoker history $(\mathrm{P}=0.036$; Table I). Higher expression levels of MED4-AS1 were significantly associated with females $(\mathrm{P}=0.02)$, poor differentiation $(\mathrm{P}=0.046)$ and lymph node metastasis $(\mathrm{P}=0.043)$ (Table II). Higher expression levels of STEAP2-AS1 were significantly associated with females $(\mathrm{P}=0.009$; Table III) and higher expression levels of SYNPR-AS1 were significantly associated with females $(\mathrm{P}=0.043)$ and adenocarcinoma $(\mathrm{P}=0.035)$ (Table IV) in this population. After the P-value was adjusted for sex, the expression of MED4-AS1 was markedly associated with poor differentiation (adj.P=0.055) and lymph node metastasis (adj.P=0.07). However, their expression levels were not significantly associated with other parameters assessed. 
Table III. The association between STEAP2-AS1 expression and clinical characteristics of NSCLC patients.

\begin{tabular}{|c|c|c|c|c|c|}
\hline \multirow[b]{2}{*}{ Characteristics } & \multirow[b]{2}{*}{$\mathrm{N}$} & \multicolumn{4}{|c|}{ Relative STEAP2-AS1 expression } \\
\hline & & Low & High & P-value & Adj.P-value \\
\hline \multicolumn{6}{|l|}{ Age (years) } \\
\hline$>65$ & 10 & 7 & 3 & 0.155 & 0.151 \\
\hline$\leq 65$ & 38 & 17 & 21 & & \\
\hline \multicolumn{6}{|l|}{ Sex } \\
\hline Male & 23 & 16 & 7 & $0.009^{\mathrm{a}}$ & \\
\hline Female & 25 & 8 & 17 & & \\
\hline \multicolumn{6}{|l|}{ Differentiation } \\
\hline Well, moderate & 36 & 18 & 18 & 0.999 & 0.839 \\
\hline Poor & 12 & 6 & 6 & & \\
\hline \multicolumn{6}{|c|}{ Tumor size (maximum diameter) } \\
\hline$>3 \mathrm{~cm}$ & 23 & 9 & 14 & 0.149 & 0.19 \\
\hline$\leq 3 \mathrm{~cm}$ & 25 & 15 & 10 & & \\
\hline \multicolumn{6}{|l|}{ Histological tumor type } \\
\hline Squamous cell carcinoma & 17 & 10 & 7 & 0.365 & 0.388 \\
\hline Adenocarcinoma & 31 & 14 & 17 & & \\
\hline \multicolumn{6}{|l|}{ Smoking history } \\
\hline Smokers & 19 & 9 & 10 & 0.768 & 0.115 \\
\hline Never smoked & 29 & 15 & 14 & & \\
\hline \multicolumn{6}{|l|}{ Lymph node metastasis } \\
\hline Positive & 21 & 9 & 12 & 0.383 & 0.489 \\
\hline Negative & 27 & 15 & 12 & & \\
\hline \multicolumn{6}{|l|}{ TNM stage } \\
\hline 1 stage & 20 & 12 & 8 & 0.242 & 0.74 \\
\hline 2.3.4 stage & 28 & 12 & 16 & & \\
\hline
\end{tabular}

${ }^{\mathrm{a}} \mathrm{P}<0.05$. Data were analyzed by Chi-square test. The high and low groups were divided by the median expression value of STEAP2-AS1 (1.240). NSCLC, non-small cell lung cancer.

\section{Discussion}

NSCLC is a common lethal cancer in the world, and the current 5-year survival rate of NSCLC remains low (26). In the present study, 2,502 differentially expressed mRNAs, 1,685 lncRNAs, and 120 miRNAs were identified in NSCLC tissues from TCGA, respectively. Further GO and KEGG analyses indicated that the differentially expressed mRNAs may participate in cellular processes (27), molecular binding (28), signal transduction and survival (29), which are important for the progression of malignant tumors. Using these differentially expressed RNAs, a ceRNA network was constructed, which reflected the relationships among different RNA transcripts. Hence, such findings may provide new insights into the pathogenesis of NSCLC.

lncRNAs are abundant in different species of animals and can regulate various biological processes and malignancies. Previous studies have revealed that tumor-associated lncRNAs not only bind to transcription factors and proteins, but also affect tumor-associated mRNAs by competitive binding to miRNAs $(30,31)$. In fact, LINC00858 was revealed to act as a ceRNA to effectively sponge
miR-422a, modulating the expression of KLK4 to impair NSCLC cell proliferation, migration and invasion (32). Similarly, ROR acted as a ceRNA of miR-145 to promote the FSCN1-mediated metastasis of esophageal squamous cell carcinoma (33). In addition, DLG1-AS1, along with miR-107 and ZHX1, formed a ceRNA network to regulate cervical cancer progression (34). MALAT1 may act as a sponger of miR-124 and attenuate the miR-124-downregulated FoxQ1 expression, regulating the progression and metastasis of bladder transitional cell carcinoma (35). In addition, the MEG3/miR-181a/HOXA11 ceRNA network and the $\operatorname{lncRNA} / \mathrm{miRNA} / \mathrm{mRNA}$ may reflect the regulatory communication among ceRNAs in multiple myeloma and colorectal carcinoma $(36,37)$. The network construction visually demonstrated that ceRNAs are key regulators in the communication among different RNA transcripts. It may reveal the intrinsic regulatory network mechanism of NSCLC at the transcriptional level. In addition, by analyzing and validating the core factors in clinical specimen data and survival data within this network, novel biomarkers may be identified to serve as diagnostic and prognostic indicators for NSCLC. Thus, the lncRNA/miRNA/mRNA 
Table IV. The association between SYNPR-AS1 expression and the clinical characteristics of NSCLC patients.

\begin{tabular}{|c|c|c|c|c|c|}
\hline \multirow[b]{2}{*}{ Characteristics } & \multirow[b]{2}{*}{$\mathrm{N}$} & \multicolumn{4}{|c|}{ Relative SYNPR-AS1 expression } \\
\hline & & Low & High & P-value & Adj.P-value \\
\hline \multicolumn{6}{|l|}{ Age (years) } \\
\hline$>65$ & 10 & 5 & 5 & \multirow[t]{2}{*}{0.999} & \multirow[t]{2}{*}{0.964} \\
\hline$\leq 65$ & 38 & 19 & 19 & & \\
\hline \multicolumn{6}{|l|}{ Sex } \\
\hline Male & 23 & 15 & 8 & \multirow[t]{2}{*}{$0.043^{\mathrm{a}}$} & \\
\hline Female & 25 & 9 & 16 & & \\
\hline \multicolumn{6}{|l|}{ Differentiation } \\
\hline Well, moderate & 36 & 16 & 20 & \multirow[t]{2}{*}{0.182} & \multirow[t]{2}{*}{0.129} \\
\hline Poor & 12 & 8 & 4 & & \\
\hline \multicolumn{6}{|c|}{ Tumor size (maximum diameter) } \\
\hline$>3 \mathrm{~cm}$ & 23 & 13 & 10 & \multirow[t]{2}{*}{0.386} & \multirow[t]{2}{*}{0.279} \\
\hline$\leq 3 \mathrm{~cm}$ & 25 & 11 & 14 & & \\
\hline \multicolumn{6}{|l|}{ Histological tumor type } \\
\hline Squamous cell carcinoma & 17 & 12 & 5 & \multirow[t]{2}{*}{$0.035^{\mathrm{a}}$} & \multirow[t]{2}{*}{0.245} \\
\hline Adenocarcinoma & 31 & 12 & 19 & & \\
\hline \multicolumn{6}{|l|}{ Smoking history } \\
\hline Smokers & 19 & 11 & 8 & \multirow[t]{2}{*}{0.376} & \multirow[t]{2}{*}{0.962} \\
\hline Never smoked & 29 & 13 & 16 & & \\
\hline \multicolumn{6}{|l|}{ Lymph node metastasis } \\
\hline Positive & 23 & 10 & 13 & \multirow[t]{2}{*}{0.386} & \multirow[t]{2}{*}{0.578} \\
\hline Negative & 25 & 14 & 11 & & \\
\hline \multicolumn{6}{|l|}{ TNM stage } \\
\hline Stage I & 19 & 10 & 9 & \multirow[t]{2}{*}{0.768} & \multirow[t]{2}{*}{0.984} \\
\hline Stages I, II or III & 29 & 14 & 15 & & \\
\hline
\end{tabular}

${ }^{a} \mathrm{P}<0.05$. Data were analyzed by Chi-square test. The high and low groups were divided by the median expression value of SYNPR-AS1 (1.545). NSCLC, non-small cell lung cancer.

ceRNA network we constructed in NSCLC extended previous findings.

In the present study, 103 lncRNAs were identified in the network that were significantly associated with prognosis, including H19, HOTAIR, MEG3, UCA1 (38-41) and other star molecules were associated with NSCLC cell proliferation, invasion and apoptosis. Among them, LINC00525, MED4-AS1, STEAP2-AS1 and SYNPR-AS1 were new 1ncRNAs and their altered expression was significantly associated with the survival of NSCLC patients. Notably, these IncRNAs were associated with clinical parameters in 48 NSCLC patients. Accordingly, these lncRNAs may be valuable biomarkers for prognosis of NSCLC patients. Notably, while the expression of MED4-AS1 and SYNPR-AS1 was upregulated in NSCLC tissues they were positively associated with OS of NSCLC patients. Such data indicated that these lncRNAs may be the tumor-stimulated compensatory lncRNAs that may, through a complex regulatory network, inhibit the progression, recurrence and metastasis of NSCLC (42). We are interested in further investigating how these IncRNAs regulate the progression of NSCLC.

Previous studies have revealed that BCAR4, XIST and SNHG3 as well as other lncRNAs are significantly elevated in NSCLC specimens (43-45) and they regulate the progression of NSCLC. In the present study, it was revealed that LINC00525, STEAP2-AS1 and SYNPR-AS1 transcripts were significantly increased in NSCLC in the TCGA and 48 NSCLC tissues we collected. Notably, the expression of MED4-AS1 was downregulated in NSCLC from the TCGA, but upregulated in 48 NSCLC specimens we collected. The discrepancy may stem from the different genetic backgrounds of patients with varying stages of NSCLC. In addition, it was revealed that the frequency of female NSCLC patients with increased MED4-AS1, STEAP2-AS1 or SYNPR-AS1 expression was significantly higher than male patients. We are interested in further examining whether these upregulated lncRNAs can regulate the expression of sex-determining region Y-box 2 (SOX2) transcription factor (46). Moreover, it was revealed that these four IncRNAs were variably expressed in different NSCLC cells. While LINC00525 was mainly present in the cytoplasm, MED4-AS1 was present in both the nucleus and cytoplasm of A549 cells. The inconsistent distribution may reflect different functions of these lncRNAs in A549 cells, supporting the notion that IncRNAs regulate the expression of many oncogenic or tumor suppressive genes at transcriptional or post-transcriptional levels (47). 
Heavy smoking is a risk factor of NSCLC. A previous study revealed that cigarette smoke exposure (CSE) increased LINC00152 expression in airway epithelial cells in a dose-dependent manner, and promoted cyclin D1 expression and G1/S transition, leading to metastasis and proliferation of NSCLC (48). In the present study, it was revealed that upregulated LINC00525 expression was positively associated with a smoking history. In fact, it was revealed in a previous study that $>50 \%$ of NSCLC cases occured in non-smoking women, and these cases were closely associated to EGFR and ALK mutations (49). In addition, upregulated MED4-AS1 expression was positively associated with poor differentiation and lymphatic node metastasis, indicating that it may promote invasion and metastasis of NSCLC. SYNPR-AS1 was positively associated with adenocarcinoma. Notably, the present study had limitations of small sample size and the lack of functional studies of individual lncRNAs. This study mainly predicted potential new biomarkers for NSCLC. Further investigations are warranted in validating the diagnostic and prognostic values of these lncRNAs and how these lncRNAs synergistically regulate the progression of NSCLC by co-expression of two or multiple lncRNAs.

In conclusion, the present data indicated that there were numerous differentially expressed lncRNAs, and along with the differentially expressed miRNAs and mRNAs, a ceRNA network was constructed. These differentially expressed mRNAs were involved in many biological processes. The expression of four selected lncRNAs was significantly associated with OS of NSCLC patients and their expression was validated in 48 NSCLC specimens we collected. These lncRNAs were significantly associated with some clinical parameters, and LINC00525 and MED4-AS1 were differentially present in the nucleus and cytoplasm of A549 cells. Therefore, these four lncRNAs may be valuable biomarkers for prognosis of NSCLC and may provide new insights in the pathogenesis of NSCLC.

\section{Acknowledgements}

Not applicable.

\section{Funding}

The present study was supported by a grant from the Shenyang Science and Technology Plan Project, Liaoning, China (Item no. 17-231-1-51). The funder had no role in the study design, the data collection and analysis, the decision to publish, or the preparation of the manuscript.

\section{Availability of data and materials}

The datasets used and/or analyzed during the current study are available upon reasonable request from the corresponding author.

\section{Authors' contributions}

XWW and QQG wrote the study, conducted the bioinformatics analysis and performed the experiments. YW, KMR and HYZ performed lobectomy to provide lung cancer specimens. TJ and FSZ performed the statistical analysis of the data. JGZ designed the project, supervised the experiments and corrected the draft. All authors read and approved the final manuscript and agree to be accountable for all aspects of the research in ensuring that the accuracy or integrity of any part of the work are appropriately investigated and resolved.

\section{Ethics approval and consent to participate}

The experimental protocol was approved by the Shengjing Hospital Ethics Committee and written informed consent was obtained from all patients.

\section{Patient consent for publication}

Not applicable.

\section{Competing interests}

The authors declare that they have no competing interests.

\section{References}

1. Hirsch FR, Scagliotti GV, Mulshine JL, Kwon R, Curran WJ Jr, Wu YL and Paz-Ares L: Lung cancer: Current therapies and new targeted treatments. Lancet 389: 299-311, 2017.

2. Kris MG, Gaspar LE, Chaft JE, Kennedy EB, Azzoli CG, Ellis PM, Lin SH, Pass HI, Seth R, Shepherd FA, et al: Adjuvant systemic therapy and adjuvant radiation therapy for stage I to IIIA completely resected non-small-cell lung cancers: American society of clinical oncology/cancer care ontario clinical practice guideline update. J Clin Oncol 35: 2960-2974, 2017.

3. Moghissi K and Dixon K: Image-guided surgery and therapy for lung cancer: A critical review. Future Oncol 13: 2383-2394, 2017.

4. Nagasaka M and Gadgeel SM: Role of chemotherapy and targeted therapy in early-stage non-small cell lung cancer. Expert Rev Anticancer Ther 18: 63-70, 2018.

5. Oak CH, Wilson D, Lee HJ, Lim HJ and Park EK: Potential molecular approaches for the early diagnosis of lung cancer (review). Mol Med Rep 6: 931-936, 2012.

6. Jarroux J, Morillon A and Pinskaya M: History, discovery, and classification of lncRNAs. Adv Exp Med Biol 1008: 1-46, 2017.

7. Sun W, Shi Y, Wang Z, Zhang J, Cai H, Zhang J and Huang D: Interaction of long-chain non-coding RNAs and important signaling pathways on human cancers (Review). Int J Oncol 53: 2343-2355, 2018.

8. Jiang N, Wang X, Xie X, Liao Y, Liu N, Liu J, Miao N, Shen J and Peng T: lncRNA DANCR promotes tumor progression and cancer stemness features in osteosarcoma by upregulating AXL via miR-33a-5p inhibition. Cancer Lett 405: 46-55, 2017.

9. Osielska MA and Jagodzinski PP: Long non-coding RNA as potential biomarkers in non-small-cell lung cancer: What do we know so far? Biomed Pharmacother 101: 322-333, 2018.

10. Qiu L, Tang Q, Li G and Chen K: Long non-coding RNAs as biomarkers and therapeutic targets: Recent insights into hepatocellular carcinoma. Life Sci 191: 273-282, 2017.

11. Vecera M, Sana J, Lipina R, Smrcka M and Slaby O: Long non-coding RNAs in gliomas: From molecular pathology to diagnostic biomarkers and therapeutic Targets. Int J Mol Sci 19: pii: E2754, 2018.

12. Xu YH, Tu JR, Zhao TT, Xie SG and Tang SB: Overexpression of lncRNA EGFRAS1 is associated with a poor prognosis and promotes chemotherapy resistance in nonsmall cell lung cancer. Int J Oncol 54: 295-305, 2019.

13. Chang L, Xu W, Zhang Y and Gong F: Long non-coding RNA-NEF targets glucose transportation to inhibit the proliferation of non-small-cell lung cancer cells. Oncol Lett 17: 2795-2801, 2019.

14. Chen ZP, Wei JC, Wang Q, Yang P, Li WL, He F, Chen HC, Hu H, Zhong JB and Cao J: Long noncoding RNA 00152 functions as a competing endogenous RNA to regulate NRP1 expression by sponging with miRNA206 in colorectal cancer. Int J Oncol 53: 1227-1236, 2018 . 
15. Chan JJ and Tay Y: Noncoding RNA:RNA regulatory networks in cancer. Int J Mol Sci 19: pii: E1310, 2018.

16. Liang YC, Wu YP, Chen DN, Chen SH, Li XD, Sun XL, Wei Y, Ning $X$ and Xue XY: Building a competing endogenous RNA network to find potential long non-coding RNA biomarkers for pheochromocytoma. Cell Physiol Biochem 51: 2916-2924, 2018.

17. Wang X, Han L, Zhou L, Wang L and Zhang LM: Prediction of candidate RNA signatures for recurrent ovarian cancer prognosis by the construction of an integrated competing endogenous RNA network. Oncol Rep 40: 2659-2673, 2018.

18. Yan Y, Yu J, Liu H, Guo S, Zhang Y, Ye Y, Xu L and Ming L: Construction of a long non-coding RNA-associated ceRNA network reveals potential prognostic lncRNA biomarkers in hepatocellular carcinoma. Pathol Res Pract 214: 2031-2038, 2018

19. Loewen G, Jayawickramarajah J, Zhuo Y and Shan B: Functions of lncRNA HOTAIR in lung cancer. J Hematol Oncol 7: 90, 2014.

20. Gutschner T, Hammerle M, Eissmann M, Hsu J, Kim Y, Hung G, Revenko A, Arun G, Stentrup M, Gross M, et al: The noncoding RNA MALAT1 is a critical regulator of the metastasis phenotype of lung cancer cells. Cancer Res 73: 1180-1189, 2013.

21. Lou X, Li J, Yu D, Wei YQ, Feng S and Sun JJ: Comprehensive analysis of five long noncoding RNAs expression as competing endogenous RNAs in regulating hepatoma carcinoma. Cancer Med 8, 5735-5749, 2019.

22. Gene Ontology Consortium: The gene ontology (GO) project in 2006. Nucleic Acids Res 34 (Database Issue): D322-D326, 2006.

23. Kanehisa M and Goto S: KEGG: Kyoto encyclopedia of genes and genomes. Nucleic Acids Res 28: 27-30, 2000.

24. Detterbeck FC, Boffa DJ, Kim AW and Tanoue LT: The eighth edition lung cancer stage classification. Chest 151: 193-203, 2017.

25. Livak KG and Schmittgen TD: Analysis of relative gene expression data using real-time quantitative PCR and the 2(-Delta Delta $\mathrm{C}(\mathrm{T})$ ) method. Methods 25: 402-408, 2001.

26. Zeng H, Zheng R, Guo Y, Zhang S, Zou X, Wang N, Zhang L, Tang J, Chen J, Wei K, et al: Cancer survival in China, 2003-2005: A population-based study. Int J Cancer 136: 1921-1930, 2015.

27. Kimmelman AC and White E: Autophagy and tumor metabolism. Cell Metab 25: 1037-1043, 2017.

28. Domschke P, Trucu D, Gerisch A and Chaplain MAJ: Structured models of cell migration incorporating molecular binding processes. J Math Biol 75: 1517-1561, 2017.

29. Franci G, Manfroni G, Cannalire R, Felicetti T, Tabarrini O, Salvato A, Barreca ML, Altucci L and Cecchetti V: Tumour cell population growth inhibition and cell death induction of functionalized 6-aminoquinolone derivatives. Cell Prolif 48: 705-717, 2015.

30. Li C, Miao R, Zhang J, Qu K and Liu C: Long non-coding RNA KCNQ1OT1 mediates the growth of hepatocellular carcinoma by functioning as a competing endogenous RNA of miR-504. Int J Oncol, Mar 12, 2018 (Epub ahead of print).

31. Mou K, Liu B, Ding M, Mu X, Han D, Zhou Y and Wang LJ: IncRNA-ATB functions as a competing endogenous RNA to promote YAP1 by sponging miR-590-5p in malignant melanoma. Int J Oncol 53: 1094-1104, 2018.

32. Zhu SP, Wang JY, Wang XG and Zhao JP: Long intergenic non-protein coding RNA 00858 functions as a competing endogenous RNA for miR-422a to facilitate the cell growth in non-small cell lung cancer. Aging (Albany NY) 9: 475-486, 2017.

33. Shang $M$, Wang $X$, Zhang $Y$, Gao $Z$, Wang $T$ and Liu R: LincRNA-ROR promotes metastasis and invasion of esophageal squamous cell carcinoma by regulating miR-145/FSCN1. Onco Targets Ther 11: 639-649, 2018.

34. Rui X, Xu Y, Huang Y, Ji L and Jiang X: lncRNA DLG1-AS1 promotes cell proliferation by competitively binding with miR-107 and up-regulating ZHX1 expression in cervical cancer. Cell Physiol Biochem 49: 1792-1803, 2018.
35. Jiao D, Li Z, Zhu M, Wang Y, Wu G and Han X: LncRNA MALAT1 promotes tumor growth and metastasis by targeting miR-124/foxq1 in bladder transitional cell carcinoma (BTCC). Am J Cancer Res 8: 748-760, 2018.

36. Shen X, Bai H, Zhu H, Yan Q, Yang Y, Yu W, Shi Q, Wang J, $\mathrm{Li} \mathrm{J}$ and Chen L: Long non-coding RNA MEG3 functions as a competing endogenous RNA to regulate HOXA11 expression by sponging miR-181a in multiple myeloma. Cell Physiol Biochem 49: 87-100, 2018.

37. Liu J, Li H, Zheng B, Sun L, Yuan Y and Xing C: Competitive endogenous RNA (ceRNA) regulation network of lncRNA-miRNA-mRNA in colorectal carcinogenesis. Dig Dis Sci 64: 1868-1877, 2019.

38. Huang Z, Lei W, Hu HB, Zhang $\mathrm{H}$ and Zhu Y: H19 promotes non-small-cell lung cancer (NSCLC) development through STAT3 signaling via sponging miR-17. J Cell Physiol 233: 6768-6776, 2018.

39. Jiang C, Yang Y, Yang Y, Guo L, Huang J, Liu X, Wu C and Zou J: Long noncoding RNA (lncRNA) hOTAIR affects tumorigenesis and metastasis of non-small cell lung cancer by upregulating miR-613. Oncol Res 26: 725-734, 2018.

40. Wu JL, Meng FM and Li HJ: High expression of lncRNA MEG3 participates in non-small cell lung cancer by regulating microRNA-7-5p. Eur Rev Med Pharmacol Sci 22: 5938-5945, 2018.

41. Nie W, Ge HJ, Yang XQ, Sun X, Huang H, Tao X, Chen WS and Li B: LncRNA-UCA1 exerts oncogenic functions in non-small cell lung cancer by targeting miR-193a-3p. Cancer Lett 371: 99-106, 2016

42. Chang N, Ahn SH, Kong DS, Lee HW and Nam DH: The role of STAT3 in glioblastoma progression through dual influences on tumor cells and the immune microenvironment. Mol Cell Endocrinol 451: 53-65, 2017.

43. Yang H, Yan L, Sun K, Sun X, Zhang X, Cai K and Song T: lncRNA BCAR4 increases viability, invasion, and migration of non-small cell lung cancer cells by targeting glioma-associated oncogene 2 (GLI2). Oncol Res 27: 359-369, 2019.

44. Li C, Wan L, Liu Z, Xu G, Wang S, Su Z, Zhang Y, Zhang C, Liu X, Lei $Z$ and Zhang HT: Long non-coding RNA XIST promotes TGF- $\beta$-induced epithelial-mesenchymal transition by regulating miR-367/141-ZEB2 axis in non-small-cell lung cancer. Cancer Lett 418: 185-195, 2018.

45. Liu L, Ni J and He X: Upregulation of the long noncoding RNA SNHG3 promotes lung adenocarcinoma proliferation. Dis Markers 2018: 5736716, 2018.

46. Zeng H, Wang J, Chen T, Zhang K, Chen J, Wang L, Li H, Tuluhong D, Li J and Wang S: Downregulation of long non-coding RNA Opa interacting protein 5-antisense RNA 1 inhibits breast cancer progression by targeting sex-determining region Y-box 2 by microRNA-129-5p upregulation. Cancer Sci 110: 289-302, 2019.

47. Renganathan A and Felley-Bosco E: Long noncoding RNAs in cancer and therapeutic potential. Adv Exp Med Biol 1008: 199-222, 2017.

48. Liu Z, Liu A, Nan A, Cheng Y, Yang T, Dai X, Chen L, Li X, Jia Y, Zhang $\mathrm{N}$ and Jiang Y: The linc00152 controls cell cycle progression by regulating CCND1 in $16 \mathrm{HBE}$ cells malignantly transformed by cigarette smoke extract. Toxicol Sci 167: 496-508, 2019.

49. Saito S, Espinoza-Mercado F, Liu H, Sata N, Cui X and Soukiasian HJ: Current status of research and treatment for non-small cell lung cancer in never-smoking females. Cancer Biol Ther 18: 359-368, 2017.

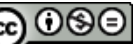

This work is licensed under a Creative Commons Attribution-NonCommercial-NoDerivatives 4.0 International (CC BY-NC-ND 4.0) License. 